\title{
Rapid life-history evolution in a wild Daphnia pulex population in response to novel size-dependent predation
}

\author{
Ingrid Wathne ${ }^{1}$ (D) $\cdot$ Katja Enberg ${ }^{1,2} \cdot$ Knut Helge Jensen $^{1} \cdot$ Mikko Heino ${ }^{1,2,3,4}$
}

Received: 18 March 2019 / Accepted: 16 January 2020 / Published online: 4 February 2020

(c) The Author(s) 2020

\begin{abstract}
The effect of size-selective predation on prey communities and their traits is well documented, but the relative roles of genetic adaptation and phenotypic plasticity continue to be debated. We looked for evidence of genetic adaption in a population of the water flea Daphnia pulex that faced a novel, introduced predator, Eurasian perch (Perca fluviatilis), selectively preying upon large zooplankton. Theory predicts adaptive changes towards a faster life history. We compared growth, age and length at maturation, egg size, and fecundity of two groups of clones kept in common-garden conditions, 13 clones isolated at around the time of the perch introduction and 14 isolated 3 years after. All animals were photographed daily and observed every third hour to detect maturation and measure the clutch size. Postintroduction clones matured earlier, but this was an indirect response triggered by genetic change in growth: post-introduction clones had faster growth prior to maturation than preintroduction ones, reaching earlier the size threshold for maturation, but the threshold itself remained unchanged. Post-introduction clones showed also higher clutch size for 2nd and 3rd clutch, and slower growth from maturation (first appearance of eggs) to the moult after the release of the first clutch. Egg size did not differ between the periods. The experiment shows how life-history responses to predation involve multiple interlinked traits and both direct and indirect genetic responses.
\end{abstract}

Keywords Contemporary evolution · Life-history evolution · Genetically-based phenotypic changes

Electronic supplementary material The online version of this article (https://doi.org/10.1007/s1068 2-020-10031-7) contains supplementary material, which is available to authorized users.

Ingrid Wathne

ingrid.wathne@uib.no

1 Department of Biological Sciences, University of Bergen, Box 7083, 5020 Bergen, Norway

2 Institute of Marine Research, Box 1870, 5817 Nordnes, Bergen, Norway

3 International Institute for Applied Systems Analysis (IIASA), 2361 Laxenburg, Austria

4 Institute of Oceanography, National Taiwan University, Taipei 106, Taiwan 


\section{Introduction}

The effect of predation on changes in life-history traits is well documented (Roff 1992; Stearns 1992), but we still know relatively little how predation structures the genetic composition of individual prey populations. Life-history theory predicts a shift in resource allocation towards the least vulnerable life-stages (Law 1979; Taylor and Gabriel 1992; Lampert 2006). For example, if small individuals are targeted, selection might favour faster growth to escape the vulnerable size ranges, whereas if large individuals are targeted, earlier maturation at smaller size might be favoured. Selection is based on phenotypes, but if the individual phenotypic differences have genetic basis, then size-selective predation will result in evolutionary change. However, predation can also affect phenotypes directly, through induced defences (Gilbert 1966; Tollrian and Harvell 1999), or by changing the environment, for example resource availability and thereby growth (Claessen et al. 2000; Enberg et al. 2012). Therefore, it may prove difficult to identify evolutionary changes and disentangle them from phenotypically plastic changes.

In this study we take advantage of a semi-natural experiment that occurred when European perch (Perca fluviatilis) was introduced to Lake Myravatn, a much-studied, small (area $0.6 \mathrm{~km}^{2}$ ) lake in Western Norway. European perch, a planktivorous fish, was in 2008 discovered to have been illegally released (Regmi et al. 2013) to this lake that previously only hosted one piscivorous fish species, northern pike (Esox lucius) (Giske 1986; Kvam and Kleiven 1995; Knudsen et al. 2006). Before the perch introduction, the lake had a characteristic, species-poor zooplankton community where unusually largesized Daphnia pulex and D. longispina, one calanoid copepod (Eudiaptomus gracilis), and larvae of phantom midge (Chaoborus flavicans) were the dominant species. Chaoborus larvae were the main predators of $D$. pulex and occurred at high densities (Regmi et al. 2013), exerting high predation pressure on small zooplankton prey (Pastorok 1981; Taylor and Gabriel 1992). The introduction of perch released the predation pressure on juvenile $D$. pulex by eliminating Chaoborus larvae from the lake, but increased vulnerability of large adults to predation (Taylor and Gabriel 1992). This complete turnover in the nature of size-selective predation, akin to the one theoretically studied by Taylor and Gabriel (1992), gave us the opportunity to study how size-dependent predation affects the life history of $D$. pulex.

We hypothesized that, first, the perch introduction caused evolution in Daphnia towards faster life history. Life-history changes that could bring about such acceleration include earlier maturation at smaller size, faster growth prior to maturation, and increased reproductive rate coupled to reduced growth after maturation. Second, the offspring quality-size trade-off should shift towards producing a larger number of smaller offspring when predation on the smallest Daphnia is relaxed. To test these hypotheses, we characterized life-history changes that occurred in Daphnia pulex from Lake Myravatn, disentangling possible genetic change from phenotypic change. Importantly, Daphnia clones collected just around the time of the perch introduction were maintained in our laboratory, allowing a direct comparison of pre- and post-introduction clones under common-garden conditions. We measured a comprehensive set of life-history traits: number of instars, growth trajectories before and after maturation, mean age and body size at maturation, probabilistic maturation reaction norm (PMRN) for age and size at maturation, egg size, and fecundity. Because the clones were reared under standardized laboratory conditions over several generations prior to the experiment, differences in 
these phenotypic traits would represent a genetically-based phenotypic change, i.e. lifehistory evolution, most likely in response to the shift in main predator from Chaoborus larvae to planktivorous fish, i.e., from negatively to positively size-dependent predation.

\section{Materials and methods}

\section{Origin and isolation of clonal lineages}

The exact timing of the perch release is unknown. Analysis of age and growth of the introduced perch suggests that it happened between late summer 2006 and spring 2007 (Regmi et al. 2013). The large ecological changes become apparent only in 2008, after the perch had successfully reproduced in summer 2007 (Regmi et al. 2013). Because the clones collected in winter 2006-2007 represent pre-introduction ecological conditions (the number of released perch was probably small), we refer to them as the pre-introduction clones, even though the actual introduction may have happened slightly before. These clones were collected by W. Lampert (Lampert et al. 2010). Seven of the clones came from females collected in December 2006 and six from ephippia (sexually produced dormant embryos), probably produced late in 2006, and collected from the surficial sediments in March 2007. The selected clones represent a random subset of all available clones (11 clones established from adults and 10 clones established from ephippia, see Lampert et al. 2010). Lampert et al. (2010) could not find significant differences in relatedness, genetic differentiation, or juvenile growth between the clones established from females or from ephippia.

Post-introduction clones were established from females collected in January-February 2010 , i.e. about 3 years after introduction of perch. Animals were sampled by vertical net hauls $(60 \mu \mathrm{m})$ from bottom to surface at the deepest part of the lake $(18 \mathrm{~m})$. Adult animals were isolated and cultured in separate glasses to create separate lineages (clones). When isolating the clones, they were maintained in aged and filtrated $(20 \mu \mathrm{m}$ and $0.20 \mu \mathrm{m})$ lake water at $19{ }^{\circ} \mathrm{C}$ and fed the green alga Scenedesmus sp. The clones were genotyped by use of microsatellites by K. Lampert [see Lampert et al. (2010, 2014) for methods for genotyping]. 13 pre-introduction and 14 post-introduction clones, in total 27 clones, were used in the experiment.

\section{Experimental setup}

For logistic reasons, the experiment was performed in three separate but procedurally identical batches, with respectively ten, seven and ten clones randomly chosen from the clone pool. Thus, each batch had up to five pre- and five post-introduction clones, with 20-30 individuals per clone, for a total of 630 individuals. Juveniles from third and fourth clutch were used to remove maternal effects (Lampert 1993). Juveniles born within 3-hour intervals were kept in $200 \mathrm{ml}$ glass jars until $45 \mathrm{~h}$ old, and then transferred individually into $70 \mathrm{ml}$ glass jars. Animals were maintained in a climate room at $19{ }^{\circ} \mathrm{C}$ with a $16: 8$ light:dark regime throughout the experiment. Water was changed every third day using artificial Daphnia medium (Klüttgen et al. 1994) modified according to Ebert et al. (1998). The animals were fed daily with Scenedesmus sp. grown in batch cultures. Each animal was fed an increasing amount of algal suspension; at 1-2 days, 3 days, 4-6 days, and then throughout the experiment 1, 2, 3 and 4 million algal cells, respectively. Cell concentrations were determined daily with a CASY1 cell counter (Schärfe System GmbH). 
For length-at-age measurements, all animals were first photographed at $45 \mathrm{~h}$; we considered juveniles too fragile for handling at an earlier stage. Thereafter, they were photographed daily until maturation, defined as the first instar with eggs visible in the brood chamber. After maturation, animals were photographed after the release of juveniles for the first three clutches. The photos were taken through a Wild stereomicroscope with a Sony DSC-17 camera. Each individual was photographed three times. The length of the animals was measured using the image analysis software ImageJ (Schneider et al. 2012). Measurements were taken from the top of the head to the base of the spine. All three measurements were averaged to obtain a length measure for each animal. When approaching time of maturation, the animals were checked every three hours until all were mature. Juveniles were counted for the first three clutches.

Egg size was measured from the photographs of females bearing their first clutch. Egg size was expressed as egg volume and estimated by assuming spheroid eggs. The volume was then calculated as $\pi / 6 d^{2} l$, where $l$ is the length of an egg along its main axis and $d$ its diameter perpendicular to the main axis. For each female, all eggs that could easily be distinguished were measured (median 4 eggs, range 1-10) and their mean was taken as the egg size of that female. Size at birth was assumed to be equal to the mean egg length over all females.

\section{Statistical analysis}

Data were analysed using (generalized) linear mixed models using the R package "lme4" (Bates et al. 2015). Detailed model output is provided in the Supplementary Materials. Egg size-body length and clutch size-body length relationships were treated as allometric relationships and estimated after log-transformation of both variables. In the first case, the null hypothesis is no relationship, corresponding to an allometric exponent of zero. In the second case, the null hypothesis is that clutch size-body size relationship has an allometric exponent equal to three. Assuming that body length-weight relationship is isometric, this corresponds to clutch size being proportional to body weight. Experimental batch was treated as nuisance factor (except for the probabilistic maturation models, where this factor was omitted for convergence reasons), with contrasts set such that the values of other model coefficients apply to the mean level of the three batches (option "contr.sum" in R). "Clone" was treated as a random effect in all analyses. In addition, "individual" was treated as a random effect where repeated measurements from a single individual were used, i.e., when estimating probabilistic maturation reaction norms (Heino et al. 2002). To account for variable duration of the time between instars, log-transformed value of instar duration (in days) was used as an offset variable (Harney et al. 2013). Error distribution in this analysis was assumed to be binomial, whereas normal distribution was used in other analyses. Likelihood ratio testing was used for testing significance of fixed effects.

\section{Results}

\section{Age and length at maturation}

Our experimental Daphnia pulex reached maturation, here defined as the instar before the release of the first clutch of eggs, after three to five post- $45 \mathrm{~h}$ instars (Table 1). Because the number of the instar at $45 \mathrm{~h}$ of age is unknown, in all that follows we will pragmatically 
Table 1 Maturation by instar number before and after the fish introduction

\begin{tabular}{llll}
\hline & Instar 3 & Instar 4 & Instar 5 \\
\hline Distribution & & & \\
Before & $30 \%(89 / 299)$ & $69 \%(205 / 299)$ & $2 \%(5 / 299)$ \\
After & $49 \%(162 / 331)$ & $49 \%(163 / 331)$ & $2 \%(6 / 331)$ \\
Maturation probability & & & \\
Before & $30 \%(89 / 299)$ & $98 \%(205 / 210)$ & $100 \%(5 / 5)$ \\
After & $49 \%(162 / 331)$ & $96 \%(163 / 169)$ & $100 \%(6 / 6)$ \\
$X^{2}$ & 23.3 & 0.134 & \\
$P$ & $<0.001$ & 0.714 & \\
\hline
\end{tabular}

Maturation for all individuals occurred during the observed instars 3-5 (instar at $45 \mathrm{~h}=1$ st observed instar). Distribution is the distribution of maturation events over instars. Maturation probability is the proportion of individuals that matured out of those that could mature (i.e., had not matured before). The $\mathrm{X}^{2}$ statistics test the independence of the latter numbers before and after the fish introduction. The nonindependence of individuals representing the same clone is ignored in this summary

define the instar at $45 \mathrm{~h}$ as the first instar of the observation period. Of the 630 tested individuals, $40 \%$ matured during the third observed instar, $58 \%$ during the fourth one, and the remaining $2 \%$ during the fifth one. Individuals from the post-introduction clones had a higher maturation probability during the third observed instar than those collected before (Table 1). Maturation probability was similar between the groups during the fourth observed instar, and all the remaining individuals matured during the fifth instar.

The average age and observed instar number at maturation was lower for the postintroduction clones compared to pre-introduction ones, but their length at maturation was marginally larger (Fig. 1). The difference was, however, only significant for age at maturation (number of observed instars, estimate \pm SE, d.f. $=1$ : $-0.23 \pm 0.13, P=0.079$; age: $-0.50 \pm 0.22 \mathrm{~d}, P=0.034$; length: $0.025 \pm 0.026 \mathrm{~mm}, P=0.344$ ). For all three cases, between-clone variability was important: the standard deviation of "clone" as a random effect is of similar magnitude as the effect of the fish introduction (number of instars, SD with $95 \%$ confidence limits: $0.32[0.22 \ldots 0.40]$; age: 0.56 [0.39 ..0.70] d; length: 0.063 [0.043...0.080] mm).

\section{Size and growth}

Post-introduction clones had larger instar-specific size for all observed instars (Fig. 2a). However, because maturation can occur at any of the instars three to five, the effect of maturation on growth might have confounded these simple estimates. Length differences for the instar at maturation and at clutches one to three were small (Fig. 2b).

Growth rate to maturation was significantly higher after the introduction, both when measured from birth (Fig. 2c: $0.030 \pm 0.013 \mathrm{~mm} / \mathrm{d}$, d.f. $=1, P=0.027$ ) and from $45 \mathrm{~h}$ (Fig. 2d: $0.029 \pm 0.014 \mathrm{~mm} / \mathrm{d}$, d.f. $=1, P=0.044$ ). In contrast, growth rate from maturation to the instar after the release of the first clutch was significantly slower after the introduction (Fig. 2e: $-0.035 \pm 0.015 \mathrm{~mm} / \mathrm{d}$, d.f. $=1, P=0.025$ ). This result is not essentially changed if growth rate is square root transformed to obtain residuals that are close to normally distributed $\left(-0.032 \pm 0.014(\mathrm{~mm} / \mathrm{d})^{1 / 2}\right.$, d.f. $\left.=1, P=0.025\right)$. No significant 
(a) Instar at maturation

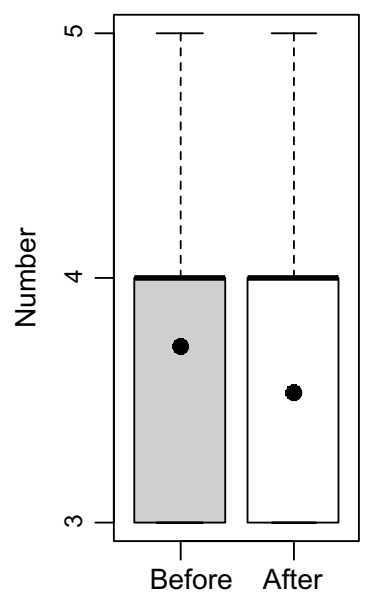

(b) Age at maturation

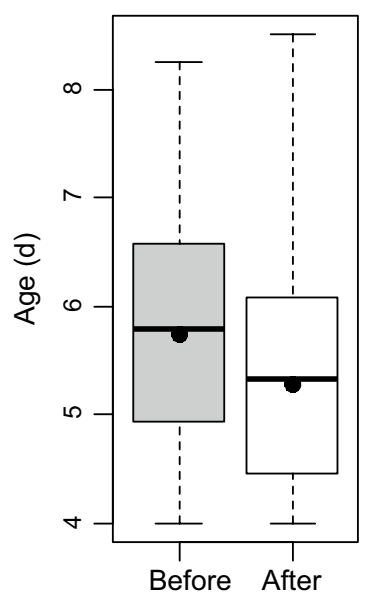

(c) Length at maturation

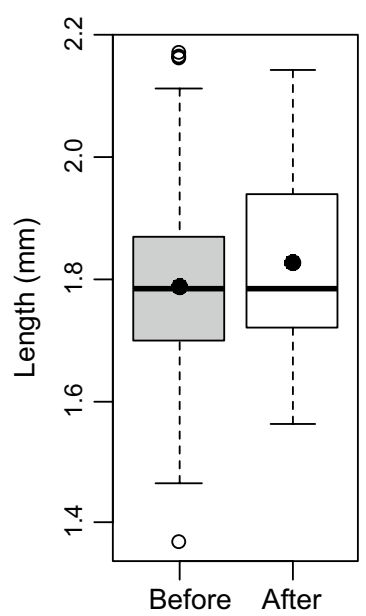

Fig. 1 Instar number (instar at $45 \mathrm{~h}=1$ st observed instar) and age and length at maturation before and after the perch introduction. The boxes show the medians and quartiles while the whiskers show the extremes within 1.5 times the interquartile range. Black circles show raw means across all individuals. The numbers of measured individuals were 299 and 331 before and after the introduction, respectively

differences were found for the growth increment between the release of the first and second clutch $(0.007 \pm 0.009 \mathrm{~mm}$, d.f. $=1, P=0.444)$, nor between the second and third clutch $(0.010 \pm 0.009 \mathrm{~mm}$, d.f. $=1, P=0.271)$.

Variability in growth was large between the clones. For example, the standard deviation of between-clone variability was $0.034[0.026 \ldots 0.043] \mathrm{mm} / \mathrm{d}$ for growth from $45 \mathrm{~h}$ to maturation, and $0.030[0.019 \ldots 0.039](\mathrm{mm} / \mathrm{d})^{1 / 2}$ from maturation to the first clutch-similar to the magnitude of the estimated difference in growth between the pre- and post-introduction clones.

\section{Dependence of maturation on age and size}

To disentangle whether earlier maturation was caused by faster growth or by lower size threshold for maturation, we estimated maturation conditional to individual age, length, and/or instar number, i.e., a probabilistic maturation reaction norm. From the outset, it is not obvious which of the said variables, or a combination thereof, best can explain maturation. Figure 3 illustrates the dependence of maturation on age, size, and instar, suggesting that maturation is primarily determined by length: both before and after the introduction, maturation probability rapidly increases from very low to very high values at around $1.6-1.7 \mathrm{~mm}$ of length. The fast-growing individuals reach this critical size range during the third observed instar, and almost all others during the fourth instar. Before the introduction, a larger proportion of 3rd instar individuals were below this size threshold than afterwards (Fig. 3a, b), in agreement with their lower overall maturation probability (Table 1).

The qualitative impression from Fig. 3 is confirmed by models for probability of maturation (Table 2). Length is the single most important explanatory variable. Age is also important and improves the model regardless whether it is measured in terms of 
(a) Size at age per instar

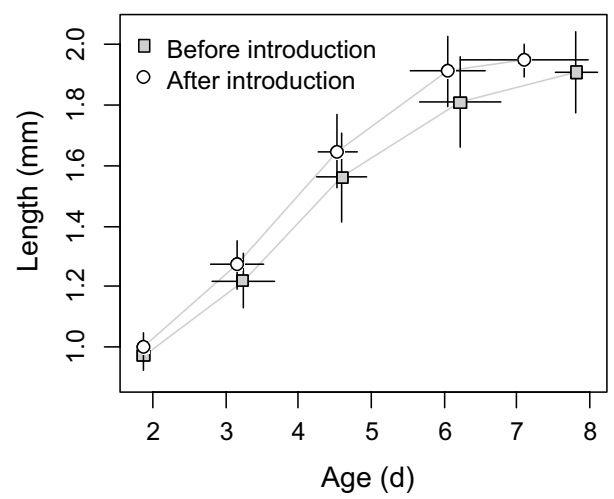

(b) Size at stage

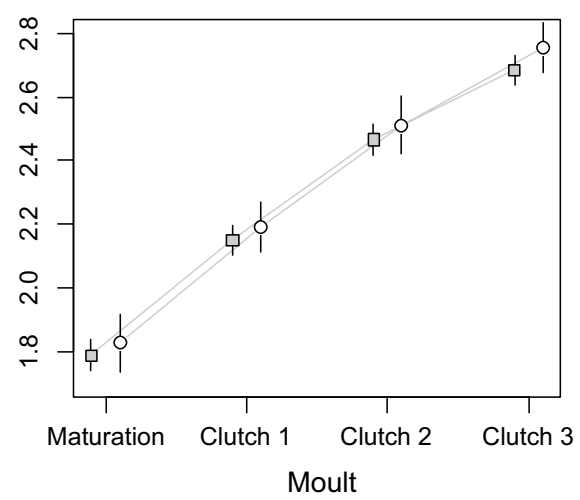

(c) Growth from birth to maturation

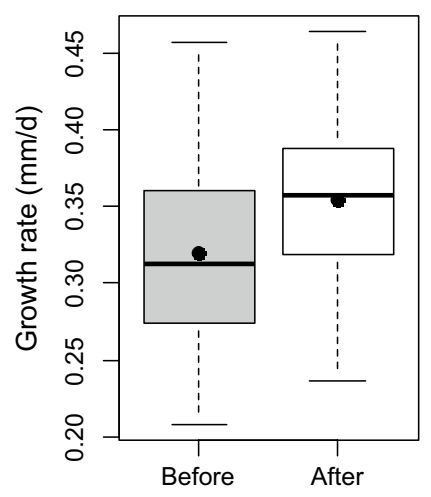

(d) Growth from $45 \mathrm{~h}$ to maturation

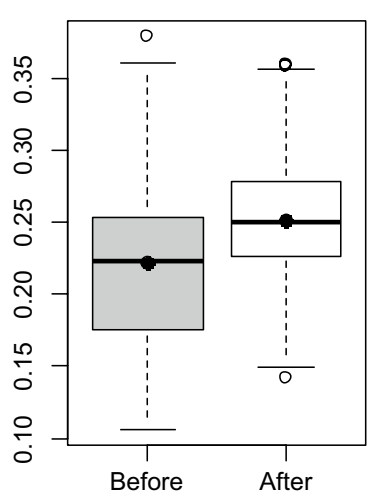

(e) Growth from maturation to 1 st clutch

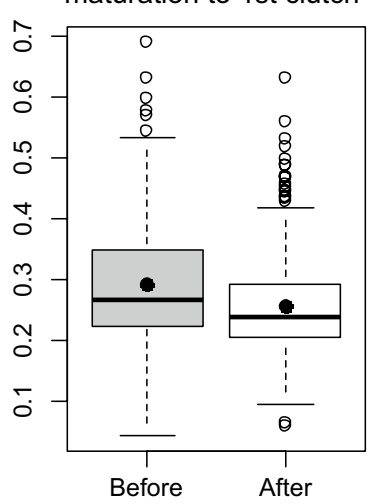

Fig. 2 Size and growth before and after the perch introduction. a Size-at-age for observed instars one to five (instar at $45 \mathrm{~h}=1$ st observed instar). Only instars up to maturation are included. b Size for instar at maturation (instar prior to release of the first clutch) and instars at clutches one to three. Age was not recorded for clutch two and three. In $\mathbf{a}, \mathbf{b}$, the error bars show one standard deviation. Box-and-whisker plots $\mathbf{c}-\mathbf{e}$ show average growth in mm per day for three different intervals, with black circles showing the raw means. In c, zero size at birth is assumed. The number of measured individuals was 630 for size at maturation and the 1st clutch, 625 for 2 nd clutch, and 434 for 3rd clutch

time or instar number. Of these two, time improves the model more than instar number $(\triangle \mathrm{AIC}=5.1)$. There is no significant difference in maturation of pre- and post-introduction clones (Table 2).

We focus then on the third observed instar (occurring between age 4 and 5 days), which shows the largest contrast between individuals that "decided" whether to mature or not (Fig. 3). Without yet considering the effects of age or size, the odds of maturation were 7.8 times higher for after-introduction clones than before (estimate $\pm \mathrm{SE}$ in $\log$ (odds): $2.06 \pm 1.05$, likelihood ratio (LR) test: $X^{2}=3.70$, d.f. $=1, P=0.055$ ). However, considering also the effect of length yields a vastly better model $\left(X^{2}=263\right.$, d.f. $\left.=1, P<0.001\right)$. Adding fish introduction to this model does not improve it $\left(\mathrm{X}^{2}=0.182\right.$, d.f. $\left.=1, P=0.662\right)$. The length threshold for $50 \%$ maturation probability from the length-only model is $1.67 \mathrm{~mm}$ (so-called PMRN midpoint), with the corresponding 25\% and 75\% maturation thresholds 
(a) Before introduction, all instars

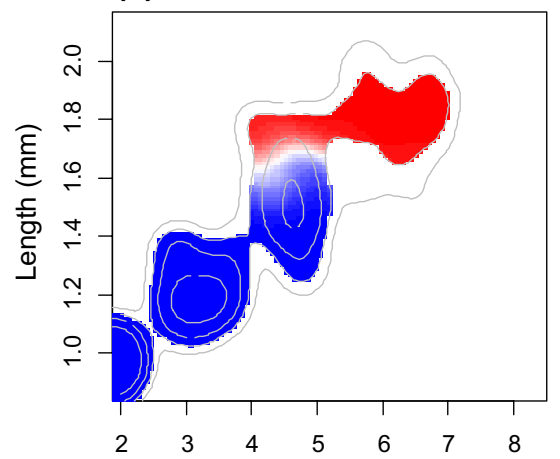

(c) Before introduction, 3rd instar

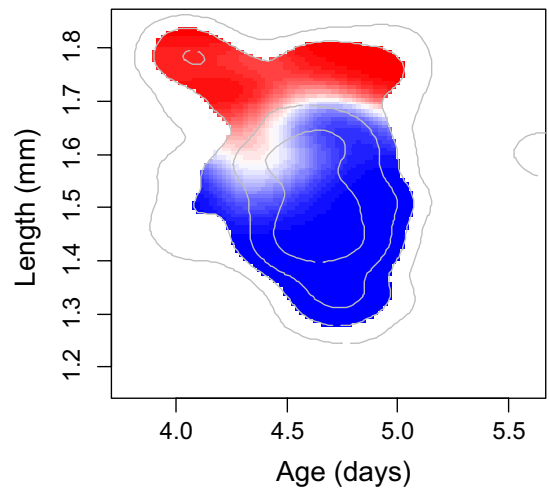

(b) After introduction, all instars

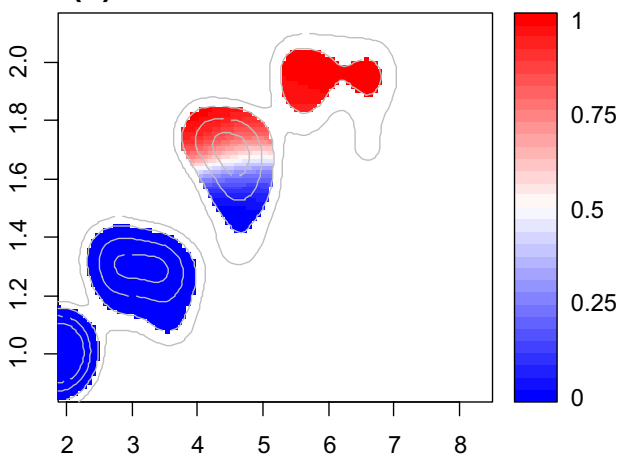

(d) After introduction, 3rd instar

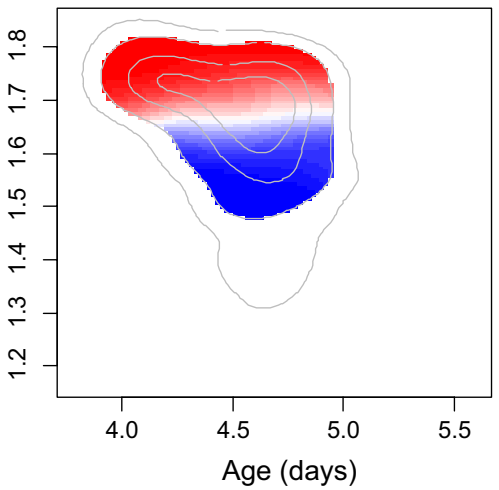

Fig. 3 Probability of maturation for all observed instars (top row) and for the third instar (bottom row; instar at $45 \mathrm{~h}=1$ st observed instar) before and after the perch introduction. The grey contour lines enclose $25 \%, 50 \%, 75 \%$, and $90 \%$ of individuals. Maturation probability (colour gradient) is calculated based on dividing the kernel density estimate of maturing individuals with that of all individuals for the combinations of age and length enclosed by the $75 \%$ contour line

Table 2 Probabilistic models for maturation for the second observed instar and later (instar at $45 \mathrm{~h}=1$ st observed instar)

\begin{tabular}{lllrc}
\hline Base model & Additional term & $X^{2}$ & $P$ & $\Delta$ AIC \\
\hline Null & Fish introduction & 2.62 & 0.106 & 1785 \\
& Length & 1786 & $<0.001$ & 0 \\
& Age & 1371 & $<0.001$ & 416 \\
& Instar number & 1541 & $<0.001$ & 246 \\
Length & Fish introduction & 1.64 & 0.200 & 31.7 \\
& Age & 33.3 & $<0.001$ & 0 \\
& Instar number & 28.2 & $<0.001$ & 5.1 \\
Length + age & Fish introduction & 0.323 & 0.570 & \\
& Instar number & 0.384 & 0.535 & \\
\hline
\end{tabular}

The results are qualitatively unchanged if all instars are included. Forward model selection is based on likelihood ratio tests. AIC is used to compare non-nested models. All models use "individual" and "clone" as random effects 
at respectively $1.64 \mathrm{~mm}$ and $1.70 \mathrm{~mm}$ (i.e., the maturation envelope). There is some indication of a positive effect of within-instar age on maturation (estimate $\pm \mathrm{SE}$ in $\log$ (odds), model with length but without introduction: $1.6 \pm 0.93$, LR test: $X^{2}=3.17$, d.f. $=1$, $P=0.075)$.

\section{Clutch and egg size}

Clutch size increased with body length (Fig. 4). For the first clutch, the allometric exponent was not different from three (estimated exponent: $2.79 \pm 0.15$, d.f. $=1, P=0.162$ ), suggesting an isometric relationship between fecundity and body weight. There was no significant difference in the clutch size of pre- and post- introduction clones (period-dependent intercept vs. null model, LR test: $\mathrm{X}^{2}=0.203$, d.f. $=1, P=0.652$ ). Moreover, while egg size increased with body length (Fig. S1), egg size-body length relationship was similar for pre- and post-introduction clones (LR test: $\mathrm{X}^{2}=1.18$, d.f. $=1, P=0.278$ ). Taken together, these results suggest that reproductive effort for the first clutch did not change between the two periods.

For the second and third clutch, the relationship between clutch size and body size differed between the two periods. While there was no overall difference in clutch size between the periods (period-dependent intercept vs. null model, LR test, 2nd clutch: $X^{2}=1.13$, d.f. $=1, P=0.288$; 3rd clutch: $\mathrm{X}^{2}=2.06$, d.f. $=1, P=0.151$ ), the model with perioddependent allometric exponent and intercept was significantly better than the null model (2nd clutch: $X^{2}=11.3$, d.f. $=2, P=0.004$; 3rd clutch: $X^{2}=11.2$, d.f. $=2, P=0.004$ ). The allometric exponent is less than three for the second and third clutch (estimated exponent without accounting for the introduction, 2nd clutch: $1.91 \pm 0.13, P<0.001$; 3rd clutch: $1.61 \pm 0.17, P<0.001)$. When the allometric exponent is period-dependent, it is lower after the introduction. Thus, these models suggest a length-fecundity relationship with higher fecundity for small- and medium-sized individuals after the introduction, but not for larger ones (Fig. 4b, c). At the mean body length across all individuals, which is $2.17 \mathrm{~mm}$ for the

(a) First clutch

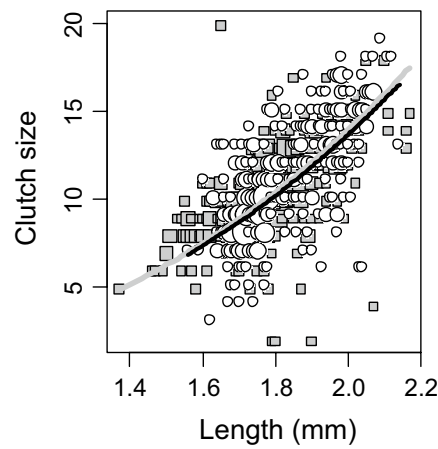

(b) Second clutch

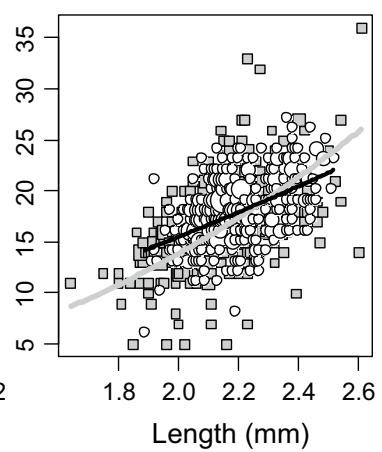

(c) Third clutch

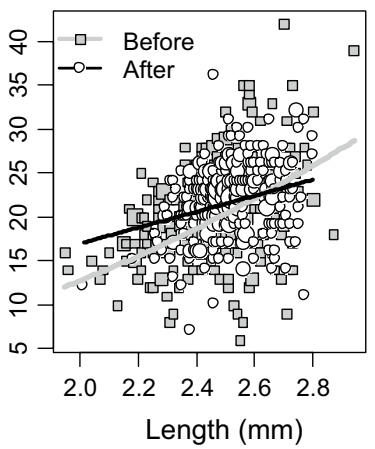

Fig. 4 The relationship between body length and clutch size before and after the perch introduction. Length refers to the body size for the instar during which the clutch is produced. Regression lines were fitted to $\log -\log$ transformed data to capture the allometric relationship. The difference in the relationship is significant for the second and third clutch. Body size is rounded to the nearest $0.01 \mathrm{~mm}$, with the area of symbol proportional to the number of observations. The number of measured individuals was 611 for the 1 st clutch, 618 for 2 nd clutch, and 617 for 3 rd clutch 
second clutch and $2.49 \mathrm{~mm}$ for the third one, fecundity is estimated to be respectively $4 \%$ and $6 \%$ higher after the introduction than before it.

\section{Discussion}

The aim of this study was to identify potential genetically-based life-history change in a population of Daphnia pulex as a result of size-dependent predation by newly introduced perch. Because we had maintained pre-introduction clones in the laboratory, without allowing for sexual reproduction, we could use a common-garden experiment to establish whether genetic adaptation had occurred between clones collected at the time of the introduction and 3 years later. Our results reveal genetic changes in growth and clutch size, and a change in maturation that was triggered by the change in growth, thus showing that predation can lead to rapid evolution of faster life history in D. pulex.

Our results show that the post-introduction clones matured earlier than the pre-introduction clones, as predicted by life-history theory (Roff 1992; Stearns 1992). However, the analysis of probabilistic maturation reaction norms (PMRNs, the size- and age-dependent maturation probabilities) did not display a significant change, showing that direct genetic adaptation in maturation was negligible or absent. Instead, growth to maturation was significantly accelerated in the post-introduction clones compared to the pre-introduction clones. This shows that the earlier maturation occurred as an indirect response to genetic change in another trait, in a similar way when maturation plastically responds to environmentallyinduced variations in growth (Stearns 1992; Heino et al. 2002): fast-growing individuals reached the size threshold for maturation described by the PMRNs earlier.

There was also a tendency towards a reduction in number of instars to maturation post introduction, but it was not significant. Several studies have shown a decrease in number of instars when Daphnia are exposed to fish (e.g., Beckerman et al. 2010). We did not count instars directly, but deduced their number from the growth curves of each individual based on frequent size measurement. However, as we needed to ensure that the animals survive the handling when photographed, the first pictures, and hence the first size measurements, were taken when the animals were $45 \mathrm{~h}$ old; younger animals proved too small and vulnerable for photographing. Instar-specific length and age distributions between the two periods are best aligned by assuming that the instar at $45 \mathrm{~h}$ corresponds to the same instar for pre- and post-introduction clones (Fig. S2-S3, see also Fig. 3). The slight shift of the length distributions towards larger sizes in post-introduction clones (Fig. S2) is consistent with an additional pre-45 h instar, but this would have been expected to lead to a parallel shift towards slightly older ages, which is opposite to what we observed (Fig. 2a). We therefore conclude that a systematic change in instar numbers before $45 \mathrm{~h}$ is unlikely, but only direct observations could have provided a conclusive answer to this question. At any rate, our main results on growth, maturation, and clutch size are not dependent on instar numbers before maturation.

We could also show a number of evolutionary changes in the adult part of the life cycle. Theoretically, we would have expected changes in energy allocation from growth towards reproduction (Roff 1992; Stearns 1992), possibly in combination with reduced energy acquisition (Enberg et al. 2012). Indeed, growth from maturation to the release of the first clutch was lower for the post-introduction clones compared to the pre-introduction clones. This could represent either reduced energy acquisition or increased allocation of energy to other purposes. We did not measure the former, whereas increased 
reproductive allocation is an obvious contender for the latter. However, the results did not show an increase in reproductive allocation, at least not in clutch size and egg size, the proxies of energetic costs of reproduction we measured. However, we did observe an increase in the size of the second and the third clutches. Growth for the corresponding time intervals did not change. Thus, we could show the theoretically predicted changes towards lesser adult growth and increased reproduction, albeit only for some of the measured parameters.

Egg size was positively correlated with female size, as observed in earlier studies (Lampert 1993). We could not detect a difference in the egg size between pre- and postintroduction clones, while life-history theory predicts that offspring size should decrease when size-dependent predation pressure during the early life history is reduced (e.g., Jørgensen et al. 2011). Note that we photographed eggs in their mother's brood pouch, which is a quick but not very precise method; more precise measurements might have revealed the theoretically predicted response.

For logistic reasons, we conducted the experiment in three consecutive but procedurally identical batches. Because we were not interested in the batches per se, we treated batch as a nuisance factor. Nevertheless, there were significant differences among the batches for all traits except clutch size (see the Supplementary Material). We are unable to identify the cause of these differences, but they might be related to the laboratory being relatively new when the experiment was started, manifested as, for example, some variation in the food quality.

Life-history changes in a population are not necessarily manifesting genetically-based phenotypic change. One of the prominent features of Daphnia is their ability to detect and respond to kairomones (chemical signals) released by predators, manifested as changes in morphology, behaviour, and life history (e.g., Spitze 1991; Stibor 1992; Stibor and Lüning 1994; Tollrian and Dodson 1999; Lass and Spaak 2003). The discovery of inducible defences (Gilbert 1966) in zooplankton resulted in a number of experimental studies (for review see Lass and Spaak 2003) aiming to separate changes in phenotype expression from direct selection effects. Importantly, these have demonstrated inducible life-history changes similar to what we have observed in our experiment. Daphnia exposed to water infused with fish kairomones reduce body size and age at maturation, and increase clutch sizes (Stibor 1992; Stibor and Lampert 2000; Beckerman et al. 2010). When exposed to invertebrate kairomones, Daphnia increase body sizes and age at maturation (Spitze 1991, 1992; Beckerman et al. 2010). We obtained Daphnia clones from their natural habitat, where they had been exposed to both direct size-dependent predation and the predator's chemical impact, during a continuous transition from invertebrate to (predominantly) vertebrate predation. However, maintaining Daphnia as asexually reproducing clones made it possible to take a snapshot of the genetic composition of a population and keep it in laboratory conditions for years. Plastic effects of predator's chemical influence will be "reset" under common-garden conditions, and hence any differences in clones collected during different size-dependent predator regimes will essentially represent a genetically-based phenotypic change.

The change in size-selection regime in Lake Myravatn has intriguing parallels with the effect of fishing on size-dependent mortality in fishes. In fishes, mortality from predation is typically negatively size-dependent (Lorenzen 1996; Sogard 1997; Perez and Munch 2010), reflecting factors such as gape limitation and other restrictions in handling of large prey (Sogard 1997; Scharf et al. 2000) as well as better predator-evasion abilities among large-sized prey (Miller et al. 1988; Lundvall et al. 1999; Schürch and Taborsky 2005). The situation for Daphnia in lakes without planktivorous fish but with Chaoborus larvae is broadly similar. 
Size-dependent mortality from fishing has a pattern that is almost exactly the opposite to natural mortality: fisheries typically target large-sized fish (Fenberg and Roy 2008; Allendorf and Hard 2009), leading fishing to be the main source of mortality for adult fish (Mertz and Myers 1998). Thus, fishing turns around the mortality regime in a way similar to what the perch introduction did in Lake Myravatn, with similar expected life-history consequences. Trends toward earlier age at maturation are commonplace in exploited fish populations (Trippel 1995), and analyses of phenotypic data using the PMRN approach indicate that such trends often have a genetic component (reviewed by Heino et al. 2015). In contrast, while we could demonstrate changes in both juvenile and adult growth, relatively few fisheries studies have addressed growth changes, and even fewer have separated juvenile and adult growth (Enberg et al. 2012; Heino et al. 2015). Similarly, changes in measures of reproductive investment such as clutch size remain little studied in exploited fish (Heino et al. 2015).

Our results with Daphnia are in agreement with the fishing-induced evolution literature in showing earlier maturation as a prominent response to positively size-dependent mortality (Audzijonyte et al. 2013; Heino et al. 2015). However, whereas most fish studies have shown that size threshold for maturation has declined, indicating a genetic change in maturation conducive to earlier maturation, we did not observe this. Instead, earlier maturation in Daphnia was a purely secondary, indirect response to faster juvenile growth, similar to phenotypic plasticity, except that the cause of faster growth here was genetic, not environmental. Evolution of faster growth in response to positively size-dependent mortality is known from theoretical models, but has not been empirically documented in exploited fish (Dunlop et al. 2009; Enberg et al. 2012).

The distinct advantage we have over observational studies on fishing-induced evolution is that we have been able to unequivocally show that organisms exposed to positively sizedependent predation genetically differed from those that had been exposed to negatively size-dependent predation. However, because we lack replication and controls, we share the same impediment as the field-based fishing-induced evolution studies in that we cannot unequivocally identify the driver of the change, that is, change in mortality, as opposed to some other change coinciding with the period of observation.

Adaptive changes in life histories, be they phenotypically plastic or genetic, will help populations to cope with changing environments (Chevin et al. 2010). Clearly, phenotypic plasticity is often advantageous because it allows rapid adjustments over time scales of individual life spans. Nevertheless, plasticity is also costly and therefore has its limits (DeWitt et al. 1998; Ernande and Dieckmann 2004). Large and persistent changes in the environment, beyond what a population has experienced in its recent evolutionary past, are likely to exceed the capacity of plasticity to buffer environmental change. The scenario in which a population's continued existence is only made possible through adaptive evolution has become to be known as "evolutionary rescue" (Bürger and Lynch 1995; Gomulkiewicz and Holt 1995; Gonzalez et al. 2013; Carlson et al. 2014). Alas, in the case of Daphnia pulex from Lake Myravatn, despite showing significant genetic changes in the life history, the environmental challenge exceeded the population's adaptive capacity: the population went extinct in about 2010/2011 (unpublished), not long after the post-introduction clones for this study were collected.

Acknowledgements Open access funding provided by University of Bergen. We thank Petter Larsson for his support and advice during this study and Winfred Lampert for collecting the pre-introduction clones. We acknowledge funding from the Bergen Research Foundation. $\mathrm{MH}$ and $\mathrm{KE}$ acknowledge funding during the final preparation of this manuscript by the Ministry of Science and Technology (MOST), R.O.C., grant number 105-2811-M-002-068, and the Research Council of Norway (project 243735), respectively. 


\section{Compliance with ethical standards}

Conflict of interest The authors declare that they have no conflicts of interest.

Open Access This article is licensed under a Creative Commons Attribution 4.0 International License, which permits use, sharing, adaptation, distribution and reproduction in any medium or format, as long as you give appropriate credit to the original author(s) and the source, provide a link to the Creative Commons licence, and indicate if changes were made. The images or other third party material in this article are included in the article's Creative Commons licence, unless indicated otherwise in a credit line to the material. If material is not included in the article's Creative Commons licence and your intended use is not permitted by statutory regulation or exceeds the permitted use, you will need to obtain permission directly from the copyright holder. To view a copy of this licence, visit http://creativecommons.org/licenses/by/4.0/.

\section{References}

Allendorf FW, Hard JJ (2009) Human-induced evolution caused by unnatural selection through harvest of wild animals. Proc Natl Acad Sci 106:9987-9994. https://doi.org/10.1073/pnas.0901069106

Audzijonyte A, Kuparinen A, Fulton EA (2013) How fast is fisheries-induced evolution? Quantitative analysis of modelling and empirical studies. Evol Appl 6:585-595. https://doi.org/10.1111/ eva. 12044

Bates DM, Märchler M, Bolker BM, Walker S (2015) Fitting linear mixed-effects models using 1me4. J Stat Softw 67:1-48. https://doi.org/10.18637/jss.v067.i01

Beckerman AP, Rodgers GM, Dennis SR (2010) The reaction norm of size and age at maturity under multiple predator risk. J Anim Ecol 79:1069-1076. https://doi.org/10.1111/j.1365-2656.2010.01703.x

Bürger R, Lynch M (1995) Evolution and extinction in a changing environment: a quantitative-genetic analysis. Evolution 49:151-163. https://doi.org/10.2307/2410301

Carlson SM, Cunningham CJ, Westley PAH (2014) Evolutionary rescue in a changing world. Trends Ecol Evol 29:521-530. https://doi.org/10.1016/j.tree.2014.06.005

Chevin L-M, Lande R, Mace GM (2010) Adaptation, plasticity, and extinction in a changing environment: towards a predictive theory. PLoS Biol 8:e1000357. https://doi.org/10.1371/journ al.pbio. 1000357

Claessen D, de Roos AM, Persson L (2000) Dwarfs and giants: cannibalism and competition in sizestructured populations. Am Nat 155:219-237

DeWitt TJ, Sih A, Wilson DS (1998) Costs and limits of phenotypic plasticity. Trends Ecol Evol 13:7781. https://doi.org/10.1016/S0169-5347(97)01274-3

Dunlop ES, Heino M, Dieckmann U (2009) Eco-genetic modeling of contemporary life-history evolution. Ecol Appl 19:1815-1834. https://doi.org/10.1890/08-1404.1

Ebert D, Zschokke-Rohringer CD, Carius HJ (1998) Within- and between-population variation for resistance of Daphnia magna to the bacterial endoparasite Pasteuria ramosa. Proc R Soc Lond B Biol Sci 265:2127-2134. https://doi.org/10.1098/rspb.1998.0549

Enberg K, Jørgensen C, Dunlop ES et al (2012) Fishing-induced evolution of growth: concepts, mechanisms, and the empirical evidence. Mar Ecol 33:1-25. https://doi.org/10.111 1/j.1439-0485.2011.00460.x

Ernande B, Dieckmann U (2004) The evolution of phenotypic plasticity in spatially structured environments: implications of intraspecific competition, plasticity costs and environmental characteristics. J Evol Biol 17:613-628. https://doi.org/10.1111/j.1420-9101.2004.00691.x

Fenberg PB, Roy K (2008) Ecological and evolutionary consequences of size-selective harvesting: how much do we know? Mol Ecol 17:209-220. https://doi.org/10.1111/j.1365-294X.2007.03522.x

Gilbert JJ (1966) Rotifer ecology and embryological induction. Science 151:1234-1237

Giske J (1986) Populasjonsregulerende faktorer hos to arter Daphnia i et vatn uten planktivor fisk [Factors regulating the populations of two Daphnia species in a lake without planktivorous fish]. Cand. Scient. thesis, University of Bergen

Gomulkiewicz R, Holt RD (1995) When does evolution by natural selection prevent extinction? Evolution 49:201-207. https://doi.org/10.2307/2410305 
Gonzalez A, Ronce O, Ferriere R, Hochberg ME (2013) Evolutionary rescue: an emerging focus at the intersection between ecology and evolution. Philos Trans R Soc B Biol Sci 368:20120404. https:// doi.org/10.1098/rstb.2012.0404

Harney E, Van Dooren TJM, Paterson S, Plaistow SJ (2013) How to measure maturation: a comparison of probabilistic methods used to test for genotypic variation and plasticity in the decision to mature. Evolution 67:525-538. https://doi.org/10.1111/j.1558-5646.2012.01758.x

Heino M, Dieckmann U, Godø OR (2002) Measuring probabilistic reaction norms for age and size at maturation. Evolution 56:669-678. https://doi.org/10.1111/j.0014-3820.2002.tb01378.x

Heino M, Diaz Pauli B, Dieckmann U (2015) Fisheries-induced evolution. Annu Rev Ecol Evol Syst 46:461-480. https://doi.org/10.1146/annurev-ecolsys-112414-054339

Jørgensen C, Auer SK, Reznick DN (2011) A model for optimal offspring size in fish, including livebearing and parental effects. Am Nat 177:E119-E135. https://doi.org/10.1086/659622

Klüttgen B, Dülmer U, Engels M, Ratte HT (1994) ADaM, an artificial freshwater for the culture of zooplankton. Water Res 28:743-746. https://doi.org/10.1016/0043-1354(94)90157-0

Knudsen FR, Larsson P, Jakobsen PJ (2006) Acoustic scattering from a larval insect (Chaoborus flavicans) at six echosounder frequencies: implication for acoustic estimates of fish abundance. Fish Res 79:84-89. https://doi.org/10.1016/j.fishres.2005.11.024

Kvam OV, Kleiven OT (1995) Diel horizontal migration and swarm formation in Daphnia in response to Chaoborus. Hydrobiologia 307:177-184. https://doi.org/10.1007/BF00032010

Lampert W (1993) Phenotypic plasticity of the size at first reproduction in Daphnia: the importance of maternal size. Ecology 74:1455-1466. https://doi.org/10.2307/1940074

Lampert W (2006) Daphnia: model herbivore, predator and prey. Pol J Ecol 54:607-620

Lampert W, Lampert KP, Larsson P (2010) Coexisting overwintering strategies in Daphnia pulex: a test of genetic differences and growth responses. Limnol Oceanogr 55:1893-1900. https://doi. org/10.4319/1o.2010.55.5.1893

Lampert KP, Regmi BP, Wathne I, Larsson P (2014) Clonal diversity and turnover in an overwintering Daphnia pulex population, and the effect of fish predation. Freshw Biol 59:1735-1743. https://doi. org/10.1111/fwb.12378

Lass S, Spaak P (2003) Chemically induced anti-predator defences in plankton: a review. Hydrobiologia 491:221-239. https://doi.org/10.1023/A:1024487804497

Law R (1979) Optimal life-histories under age-specific predation. Am Nat 114:399-417

Lorenzen K (1996) The relationship between body weight and natural mortality in juvenile and adult fish: a comparison of natural ecosystems and aquaculture. J Fish Biol 49:627-642. https://doi. org/10.1111/j.1095-8649.1996.tb00060.x

Lundvall D, Svanbäck R, Persson L, Byström P (1999) Size-dependent predation in piscivores: interactions between predator foraging and prey avoidance abilities. Can J Fish Aquat Sci 56:1285-1292. https://doi.org/10.1139/f99-058

Mertz G, Myers RA (1998) A simplified formulation for fish production. Can J Fish Aquat Sci 55:478-484

Miller TJ, Crowder LB, Rice JA, Marschall EA (1988) Larval size and recruitment mechanisms in fishes: toward a conceptual framework. Can J Fish Aquat Sci 45:1657-1670. https://doi.org/10.1139/ f88-197

Pastorok RA (1981) Prey vulnerability and size selection by Chaoborus larvae. Ecology 62:1311-1324. https://doi.org/10.2307/1937295

Perez KO, Munch SB (2010) Extreme selection on size in the early lives of fish. Evolution 64:24502457. https://doi.org/10.1111/j.1558-5646.2010.00994.x

Regmi BP, Wivegh JS, Hobæk A (2013) Population decline and life-cycle changes in a phantom midge (Chaoborus flavicans) after introduction of planktivorous fish. Freshw Biol 58:1436-1446. https:// doi.org/10.1111/fwb.12141

Roff DA (1992) The evolution of life histories. Theory and analysis. Chapman and Hall, New York

Scharf FS, Juanes F, Rountree RA (2000) Predator size-prey size relationships of marine fish predators: interspecific variation and effects of ontogeny and body size on trophic-niche breadth. Mar Ecol Prog Ser 208:229-248. https://doi.org/10.3354/meps208229

Schneider CA, Rasband WS, Eliceiri KW (2012) NIH Image to ImageJ: 25 years of image analysis. Nat Methods 9:671-675. https://doi.org/10.1038/nmeth.2089

Schürch R, Taborsky B (2005) The functional significance of buccal feeding in the mouthbrooding cichlid Tropheus moorii. Behaviour 142:265-281. https://doi.org/10.1163/1568539053778274

Sogard SM (1997) Size-selective mortality in the juvenile stage of teleost fishes: a review. Bull Mar Sci 60:1129-1157 
Spitze K (1991) Chaoborus predation and life-history evolution in Daphnia pulex: temporal pattern of population diversity, fitness, and mean life history. Evolution 45:82-92. https://doi. org/10.2307/2409484

Spitze K (1992) Predator-mediated plasticity of prey life history and morphology: Chaoborus americanus predation on Daphnia pulex. Am Nat 139:229-247. https://doi.org/10.1086/285325

Stearns SC (1992) The evolution of life histories. Oxford University Press, Oxford

Stibor H (1992) Predator induced life-history shifts in a freshwater cladoceran. Oecologia 92:162-165. https://doi.org/10.1007/BF00317358

Stibor H, Lampert W (2000) Components of additive variance in life-history traits of Daphnia hyalina: seasonal differences in the response to predator signals. Oikos 88:129-138. https://doi.org/10.103 4/j.1600-0706.2000.880115.x

Stibor H, Lüning J (1994) Predator-induced phenotypic variation in the pattern of growth and reproduction in Daphnia hyalina (Crustacea: Cladocera). Funct Ecol 8:97-101. https://doi. org/10.2307/2390117

Taylor BE, Gabriel W (1992) To grow or not to grow: optimal resource allocation for Daphnia. Am Nat 139:248-266

Tollrian R, Dodson SI (1999) Inducible defenses in Cladocera: constraints, costs, and multipredator environment. In: Tollrian R, Harvell CD (eds) The ecology and evolution of inducible defenses. Princeton University Press, Princeton, pp 177-202

Tollrian R, Harvell CD (eds) (1999) The ecology and evolution of inducible defenses. Princeton University Press, Princeton

Trippel EA (1995) Age at maturity as stress indicator in fisheries. Bioscience 45:759-771. https://doi. org/10.2307/1312628

Publisher's Note Springer Nature remains neutral with regard to jurisdictional claims in published maps and institutional affiliations. 